Daniel Candel*

\title{
Extending the embodied semiotic square: A cultural-semantic analysis of "Follow your Arrow"
}

https://doi.org/10.1515/sem-2018-0144

\begin{abstract}
Pelkey's anchoring of the semiotic square in embodiment is excellent news for cognitive literary theory, a dynamic field still in search of itself. However, his validation of the square, though theoretically unexceptionable, suffers in the execution, for his interpretation of the country song "Follow your Arrow" is less successful. The present article benefits from Pelkey's validation as it organizes a tool of cultural-semantic analysis (CS-tool) as a 'deviant' semiotic square. The article then shows how this particular semiotic square allows us to analyze the song in terms which build on Pelkey's analysis, but also arrive at more satisfying results. Where Pelkey sees liberation in the song and the square, the tool uncovers manipulation in the former and closure in the latter. The article then assesses the complementarity of and differences between the two squares: Pelkey works on a local sentence-level through direct implicature, thus following the narrative/ authorial voice of the poem. The CS-tool starts from a position of higher abstraction requiring a less defined, but still sufficient and more wide-ranging, three-step implicature. This allows the tool to step back from the song's authorial voice and uncover its manipulations. The article closes by discussing the deviant features of the present square.
\end{abstract}

Keywords: cognitive literary theory, CS-tool, embodiment, semiotic square

\section{Introduction}

Cognitive literary studies is proving a fascinating battlefield (Baumbach et al. 2017). At present, literary cognitivism holds solid and popular niche status (Herman 2013; Müller-Wood 2017). Handbooks have been produced and special issues are increasingly common in the specialized literary journals'.1 Whether cognitive literary theory will ultimately establish itself as a recognized discipline or slowly languish and die out because of its inability to provide a coherent account of

*Corresponding author: Daniel Candel, Universidad de Alcalá, Alcalá de Henares, Spain, E-mail: daniel.candel@uah.es 
literature/narrative is still an open issue, but cognitive studies as a whole is immersed in a similar process (Cowart 2014: 260; see also Liesbeth 2014). Meanwhile, literary cognitivism has been upgraded to a "second generation" (Kukkonen and Caracciolo 2014: 261) and the brain and its cognitive processes moved away from the computer and towards the body. The body is now present in the brain in a variety of ways, among which are the necessary connection between perception, body and environment (Varela et al. 1991), the body's kinesthetic and spatial experience and its influence on thought and language (Lakoff and Johnson 1980), the insignificant proportion of conscious versus unconscious brain activity (Vermeule 2015), or bio-evolutionary approaches to the brain and thinking critical with the accounts of evolutionary literary critics (Easterlin 2012: 18; Zunshine 2015: 2).

Some proponents of cognitive literary theory praise this variety (Zunshine 2015). Others try to contain variety's overspill into the poststructuralist chaos to which cognitive studies originally emerged as a response (Colm Hogan 2015; Crane 2015). At present it seems that attempts to minimize such overspill focus on ordering the field, for example by "map[ping] the continuum between our biological make-up and socio-cultural meaning-making” (Caracciolo 2014: 399), or by providing a differentiated typology of the relationship between cognition and interpretation (Caracciolo 2016). Again, whether containment through organization is the beginning of a sustainable program or just another strategy to claim artificial mastery over an ungovernable field ${ }^{1}$ is still to be seen and is currently being addressed (Baumbach et al. 2017). Critics of literary cognitivism, in any case, sharpen their pens, lambasting it for offering pre- or a-narrative in lieu of 'narrative' cognitive findings (Sternberg 2003, 2009), for being unable to define embodiment, cognitivism's most basic category, refusing to use scientific data drawn from mainstream cognitivism, and failing to establish cognitive/natural invariants which might limit the field of enquiry (Müller-Wood 2017), or for not being able to bridge the gap between cognition and culture (Hartner 2017).

In such a scenario, anchoring Greimas' semiotic square in embodiment, as Pelkey (2017) has done, is no mean milestone for cognitivists, literary and otherwise. Pelkey has compellingly shown - for which he has been awarded the 2017 Mouton d'Or - that the semiotic square is grounded in kinesthesia and proprioception, related terms signaling our awareness of the different parts of our body, their movement and effort in moving them. In doing so, Pelkey has given biological substance to Greimas' unproven dictum that semiotic squares are "deep structures" with a "definable logical status" (Greimas and Rastier 1968: 87). At the end

1 Notice the readiness of cognitive literary studies to reduce literature/narrative to cognitive parameters (Caracciolo 2016: 202) and its simultaneous criticism of other approaches to literature for doing something similar (Zunshine 2015: 2). 
of the article, Pelkey analyzes parts of the country music song/video "Follow your Arrow," 2 to show how the visual and notional structure of the song can be captured by an embodied semiotic square.

Pelkey's move is thus a double one: he proves the validity of the semiotic square and enacts it through analysis and interpretation. However, Pelkey's interpretation of "Follow your Arrow" is not complete or ultimately correct. I will argue that the act of enacting validity can be improved on, but with a different kind of semiotic square. In the present article, I will therefore 'construct' such a different semiotic square out of a cultural-semantic tool of analysis I have developed (Candel 2013a, 2013b, 2013c, 2016, 2018a, 2018b) henceforth called CS-tool. The square has its own distinctive features, wherefore I will above all use Pelkey's, but also other arguments, to ground this particular square in cognitive theory (Section 3). I will then analyze "Follow your Arrow," first by summarizing Pelkey's analysis (Section 4), and then by analyzing the song with the CS-tool (Section 5). I will argue for the complementarity of both analyses, as they touch on different levels of the song's meaning, but also for the ultimate correctness of the one carried out with the CS-tool, as it goes beyond Pelkey's analysis, which it nevertheless presupposes, and can cover the whole poem rather than parts of it, thus digging deeper and wider (Section 6). Finally, I will briefly summarize the differences that emerge from a comparison between the classic semiotic square and the CS-tool as a semiotic square, with regard to the square itself, to interpretation and to embodiment (Section 7). First, however, I will provide a brief summary of Pelkey's validation of the semiotic square as an embodied structure, and its significance for ideological analysis (Section 2).

\section{Pelkey's embodied semiotic square}

Pelkey shows how the relations existing between the different terms in the semiotic square are based on "salient features of human evolution," above all "the experience of upright posture and the distinctive reorganization of proprioception and kinesthesia this posture enables, relative to (and co-requisite with) limb specialization and the marked functional reconfiguration of the anatomical planes" (2017: 278). In plain language, walking on two legs has altered our feeling towards, and orientation and specialization of, our body parts and their movement. Out of these "we derive basic structural awareness of opposition and contrast" (2017: 277), which emanate from different bodily experiences, above all verticality, the distinction between up and down (2017: 279-280), laterality, the distinction between right and

2 The song is part of Kacey Musgraves 2013 album Same Trailer Different Park and was awarded a Grammy the following year. 
left (2017: 283-285), and transversality, the blend of our experience of verticality and laterality by cutting the body through the waist, and vertically from left to right and front to back (2017: 287). These three experiences of the body correspond to the diagrammatic representation of a semiotic square (see Figure 1).

Pelkey further argues that what looks like a perfectly symmetrical diagram is experienced by the body in asymmetrical ways, as specifically laterality tends to favor right over left. Thus, hands and face match only imperfectly, hands not even when rotated (2017: 285, 292), a situation in which right is generally favored over left in both nature and the human body (2017: 285). Manual "dextrality," as the phenomenon is called, is extended to culture, for right - Latin dexter - is also associated across languages with what's good and left - Latin sinister - with what's bad (2017: 285). Binary oppositions follow this very schema, with the positive, unmarked term coming first, to the right and the negative, marked value following to the left - the left we see being the right we naturally experience and vice versa (2017: 286). The hierarchy of unmarked/marked is thus an embodied relationship. Laterality through cultural dextrality is quite obvious in Greimas' semiotic square, where the favored, unmarked $s_{1}$ appears in the perceived upper right-hand corner of the diagram and the less favored, marked term in $s_{2}$, in the perceived upper left-hand corner. It is also apparent in the distinction between upper $\left(\mathrm{s}_{1}, \mathrm{~s}_{2}\right)$ and lower half $\left(\overline{\mathrm{s}}_{1}, \overline{\mathrm{s}}_{2}\right)$.

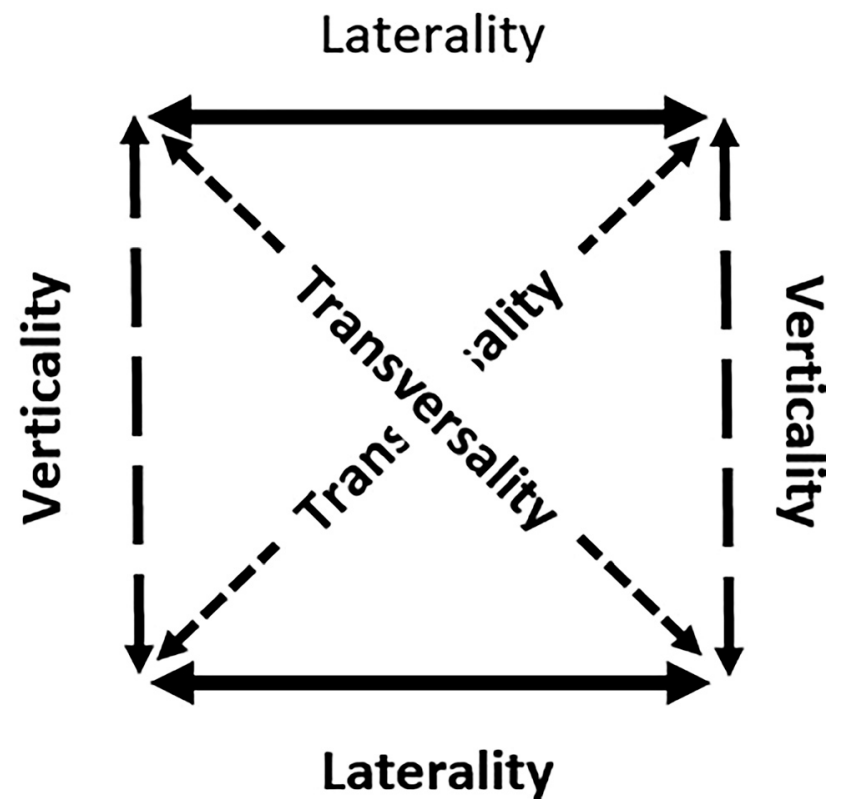

Figure 1: The body in the semiotic square. 


\section{Using Pelkey's account of embodiment to structure a CS-tool}

The tool I propose can be thought of as starting with the well-known and basic opposition nature - society.3 Such an opposition is binary and hierarchizes its terms: 'physics' comes first and is unmarked, while 'nomos' comes second and is marked, both in cultural (Spaemann 1994) as well as evident evolutionary terms, which does not preclude nature from being thoroughly imbricated in culture and the other way round (Carroll 2005; Midgley 2001: 38-39, 42-44).3 As we have seen, this cultural unmarked/marked opposition is based on the body schemas lateralization and dextrality. As of yet, this only allows for a C(ultural) or C-tool, as it only uses the cultural terms nature/society. Such a tool is, however, linked to semantics and can thus become a C(ultural) S(emantic) or CS-tool because the opposition nature/society is validated from the perspective of logic and linguistics by distinguishing alethic from deontic modalities, two distinctively different ways of being in the world (aletheia is Greek for 'truth,' while deon is Greek for 'duty'). The CS-tool's connection with modality may confer the tool an added cognitive basis: some cognitive linguists dispute the existence of modality as a cognitive category (Mortelmans 2007: 869). Others, however, consider modality a bioevolutionary feature of thinking and speaking linked to displacement (von Fintel 2006), one of a set of 'design features' or characteristics of human communication which sets it apart from animal communication (Hockett and Altmann 1968).3 In addition, in practice mood and modality function as a language universal, as they are found in virtually all languages across the world in one way or another (Nauze 2008).

The specific link between physis/nomos and modality gives rise to a further unmarked/marked opposition, and thus strengthens the body schemas lateralization and dextrality: In the alethic modality, necessity (the natural) acts as the unmarked and impossibility (the supernatural) as the marked term, as the prefix 'super' shows, with possibility remaining as the neutral term. In the deontic modality, however, it is more difficult to distinguish the unmarked obligation (duty to do) from the unmarked prohibition (duty not to do), as we can equally experience both as constraints on our freedom (permission acts as the neutral term). In fact, in the alethic-deontic binary, nature knows two basic oppositions in which it appears as the unmarked term, one where it is opposed to society, thus overcoming the alethic-deontic divide, the other opposing the supernatural, within the alethic modality (see Figure 2).

Another possible way of constructing the double binary in which nature appears as unmarked is by placing nature in the middle of a continuum that leads 


\begin{tabular}{|c|c|c|c|c|c|}
\hline \multirow{4}{*}{ Alethic } & Unmarked & Marked & Unmarked & Marked & \multirow{4}{*}{ Deontic } \\
\hline & Nature & Supernatural & Obligation? & Prohibition? & \\
\hline & \multicolumn{2}{|c|}{ Unmarked } & \multicolumn{2}{|c|}{ Marked } & \\
\hline & \multicolumn{2}{|c|}{ Nature } & \multicolumn{2}{|c|}{ Society } & \\
\hline
\end{tabular}

Figure 2: Double unmarked status of nature.

from the supernatural to nature to society or the reverse. This, however, feels anomalous, as the difference between levels - within the alethic, between the alethic and the deontic - is erased, and the very embodiment through laterality and dextrality compromised. Another, more general problem, is that, whatever the presentation, the alethic and deontic neutral terms - possibility and permission do not appear in the binaries and somehow suggest an incomplete theory.

It is here that that the CS-tool is best reorganized into Greimas' semiotic square by adding something. This, however, requires a little detour into modality: discussions of the deontic modality regularly show that the deontic rule can be transgressed (Doležel 1998: 122; Wright 1968: 61, 65). In cultural terms, transgression allows for the incorporation of individuality as a counterweight to society, just as the supernatural acts as a counterweight to nature. Modally, individuality fits perfectly into the semantic spaces left free by the alethic operator possibility - the expression of individuality is bound by what is 'possible' - and permission - the exercise of individuality is limited to what society 'permits'. While modally, individuality thus fits the space provided by possibility and permission, culturally it often acts in opposition to the other terms, especially society: from a culturally evolutionist position, i.e., the point of view of Enlightenment morality, the expression of individuality is usually predicated as the rebellion of the individual against socially and religiously sanctioned strictures (MacIntyre 2007), and in the 21st century, increasingly and who knows if in selfdestroying ways, against the dictates of nature (Adorno and Horkheimer 1988; Peterson 2018).

The irruption of individuality allows for the creation of a new organizing system, more complex, but respectful with the totality of modality and with culturally evolutionist views and nevertheless embodied, as we can now organize the four terms in a semiotic square (see Figure 3).

As regards embodiment, to laterality and dextrality we can now add verticality and transversality. As for the semiotic square itself, Figure 3 shows how it is different from a traditional semiotic square based on semes or sememes. The first, 


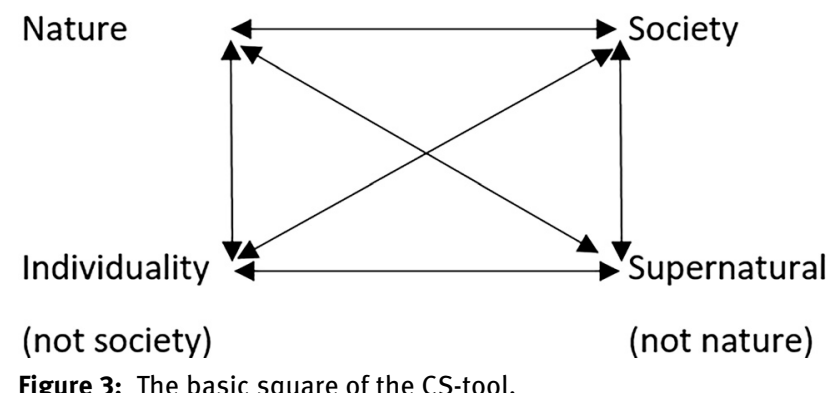

easily identifiable difference is that the lower terms are not really phrased as negations of the upper terms (not nature, not society), but have their own identity, even though, as we have argued, the supernatural is really a subordinate term with regard to nature. The case of individuality also gestures towards subordination, especially when translated into roughly equivalent terms like uniqueness and freedom: such terms are best left on their own, for the moment one inquires further, these terms show their indebtedness: freedom tends to be freedom from something or for something, individuality and uniqueness are also best understood when contrasted to patterned behavior (Pinckaers 1995: 242-243; Ricoeur 1992: 2, 28). The multiple paradox emerges that, while the supernatural and individuality are conceptually subordinated to nature and society, they also stand in opposition to their superordinate terms, have their own cultural meaning, and can thus not be equated with 'not nature' or 'not society'.

The second difference stems from the first: while in a traditional semiotic square, the vertical relations are relations of implication (society is implied in not nature, nature in not society), implication is simply not present in the relationship society-supernatural or nature-individuality. In fact, one wonders what kind of logical relationship applies now for three of the possible binaries in the square, for society and the supernatural do not simply oppose each other, and neither do nature and individuality or individuality and the supernatural. In fiction and real life, however, these relationships do exist: the combination of individuality and the supernatural leads to theological nominalism (Pinckaers 1995: 240-247), the combination of nature and individuality leads to emotionalism (MacIntyre 2007), and the combination of the supernatural and society leads to feelings evoked by totalitarian states and well described by Orwell in 1984 or Solzhenitsyn in The Gulag Archipelago. The terms can just as easily oppose each other. Since these relationships thus exist and academics should first acknowledge existence and then bother about how to deal with it, I would like to take the best of two arguments, fuse the semiotic square with the CS-tool, as in Figure 4, and then see what happens when I use the tool to analyze. 


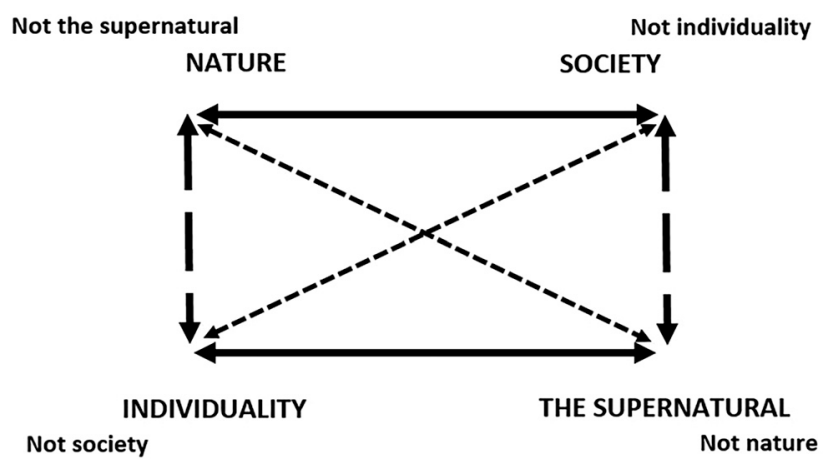

Figure 4: Fusing the semiotic square with the CS-tool.

Thus fusing the traditional semiotic square with the CS-tool will also allow me to refine my analysis of "Follow your Arrow" and maybe find out whether the traditional terminology - 'not nature'/'not society' - is more useful for analysis than that of the CS-tool - the supernatural/individuality - or whether it is best to use the two terminologies in complementary ways.

\section{Pelkey's analysis of "Follow your Arrow"}

According to Pelkey, there are three "basic" themes in Kacey Musgraves' country song "Follow your Arrow": "1) the psychological stress of living under ideological/ psychological 'double-binds,' 2) the jolt of identifying them, and 3) the joy of breaking free from them" (2017: 297). Pelkey's analysis of the song with semiotic squares thus rests on the tripartite sequence ideological aporia (step 1), awareness of (step 2), and freedom from (step 3), aporia. Pelkey uses the semiotic square to analyze step 1 of this sequence, the ideological double bind, and does so by selecting the first and last of the four aporias which appear in the lyrics of the song:

1. If you save yourself for marriage/You're a bore

If you don't save yourself for marriage/You're a whore-ible person

4. If you don't go to Church/You'll go to hell

If you're the first one/On the front row/You're self-righteous/Son of a -

Each of the terms of the two aporias is placed in a semiotic square, and interpreted through implicature where necessary (aporia one is shown in Figure 5 as presented by Pelkey). 
Pelkey then shows ways in which the video recalls the embodied aspect of this particular organization of the double binds, through the scenery - a combination of desert landscapes and motels - or the repeated use of arrows. Above all, and as diagrammatically shown in Figure 5, Pelkey points out a "Priest's spread-eagle jump" in the middle of the chorus, "a point of psychic breakthrough" (2017: 298). According to Pelkey, the X-form of the priest is a call of attention to the embodied presence of the semiotic structure of the double bind. Pelkey uses this example to argue, with Jameson, for the dual nature of the square with regard to ideology, for while on the one hand the square "represents ideological closures" by providing a closed conceptual system (2017: 295), awareness of closure itself, in this case in the presence of the embodied X, can lead us to look for loopholes to break through the logic of the square (2017: 298).

\section{Applying the CS-tool as a semiotic square to "Follow your Arrow"}

I am now going to analyze "Follow your Arrow" with the CS-tool, although, rather than look at some of its elements, I will analyze the whole song. In Figure 6 the

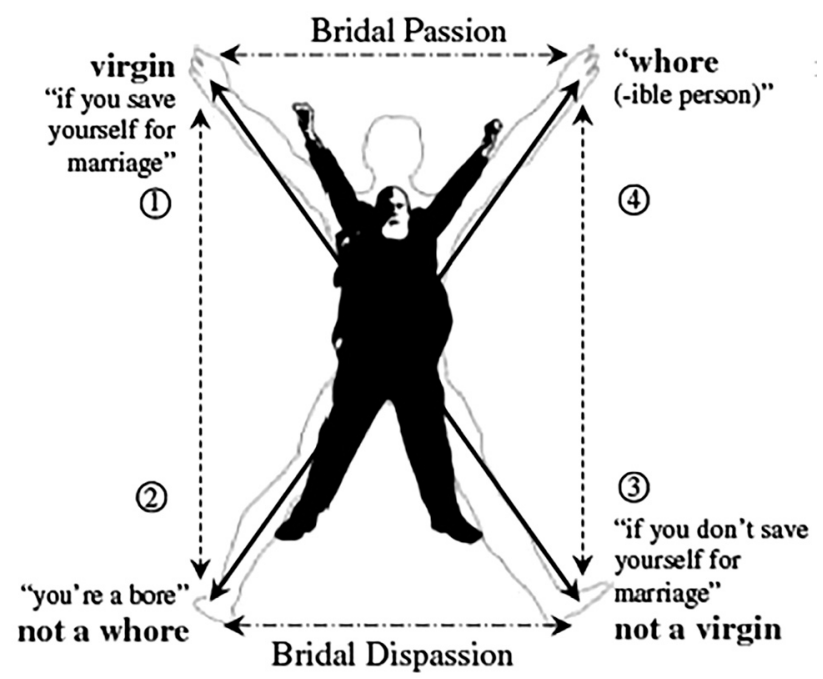

Figure 5: Aporia one in Pelkey. 
lyrics are divided into four colors which reflect Pelkey's progression of the song in three steps:

Step 1. Red and blue are awarded for those parts of the song which show the "ideological/psychological 'double-binds'," one color for each kind of bind; bold type is used to highlight the cause against the effect of each double bind. There are four double binds, so they are numbered from one to four. Double-bind three appears in black because it cannot be analyzed with the CS-tool.

Step 2. Passages in green mark moments where the narrative/authorial voice shows awareness of her situation.

\begin{tabular}{|c|c|c|}
\hline 1. If you save yourself for & You're damned if you do & 4. If you don't go to church \\
\hline marriage & And you're damned if you don't & 4. You'll go to hell \\
\hline 1. You're a bore & So you might as well just do & 4. If you're the first one \\
\hline 1. If you don't save yourself & Whatever you want & On the front row \\
\hline for marriage & $1^{\text {st }}$ CHORUS: & 4. You're a self-righteous \\
\hline 1. You're a whore-able person & So make lots of noise & Son of a- \\
\hline 2. If you won't have a drink & Kiss lots of boys & Can't win for losing \\
\hline 2. Then you're a prude & Or kiss lots of girls & You just disappoint 'em \\
\hline 2. But they'll call you a drunk & If that's something you're into & Just 'cause you can't beat 'em \\
\hline 2. As soon as you down the & When the straight and narrow & Don't mean you should join 'em \\
\hline first one & Gets a little too straight & $2^{\text {nd }}$ CHORUS \\
\hline 3. If you can't lose the weight & Roll up the joint, or don't & Say what you feel \\
\hline 3. Then you're just fat & Just follow your arrow & Love who you love \\
\hline 3. But if you lose too much & Wherever it points, yeah & 'Cause you just get \\
\hline \multirow[t]{5}{*}{ 3. Then you're on crack } & Follow your arrow & So many trips 'round the sun \\
\hline & Wherever it points & Yeah, you only \\
\hline & & Only live once \\
\hline & & $3^{\text {rd }}$ CHORUS \\
\hline & & (Roll up the joint, I would) ${ }^{1}$ \\
\hline
\end{tabular}

Figure 6: Analysis of "Follow your Arrow" with the CS-tool. 


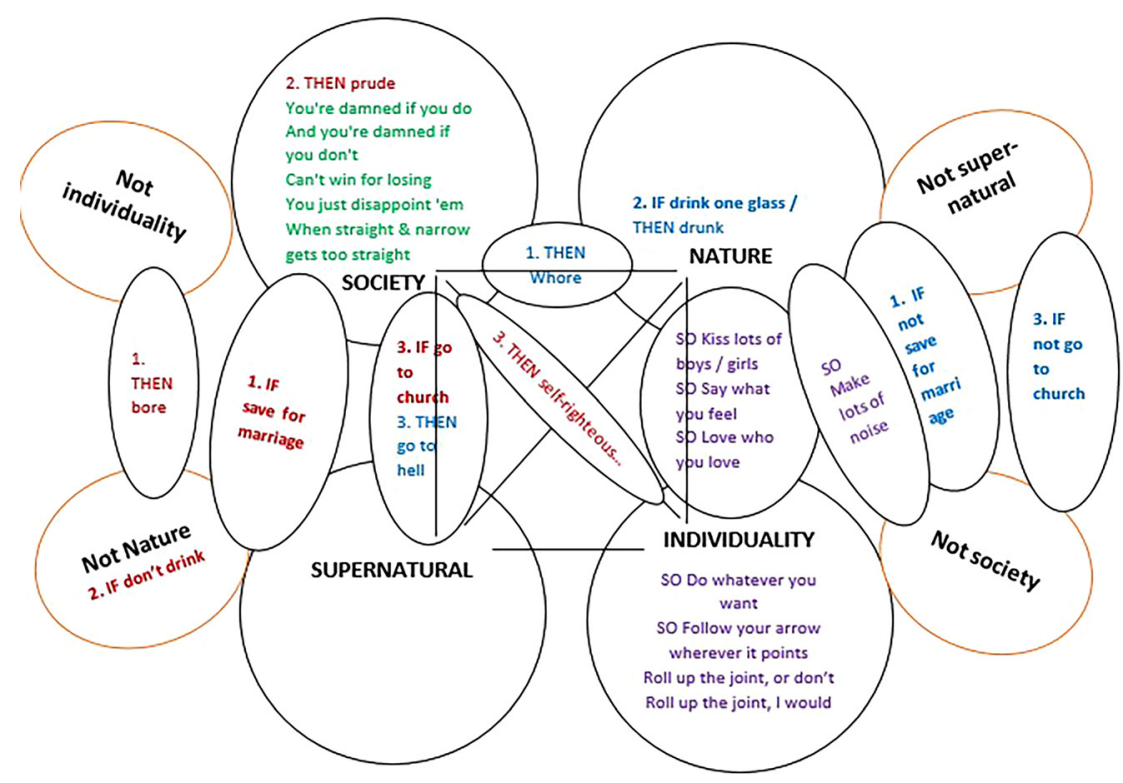

Figure 7: Color distribution in the square.

Step 3. Passages in violet mark those moments in which the narrative/authorial voice breaks free from the double binds.

The different lines (minimally modified for comprehension) are now allotted to the terms which signify them in the semiotic square of the CS-tool (see Figure 7).

As we can see, Figure 7 represents a semiotic square (see straight lines) in which $s_{1}$ is 'society' (this will have to be explained later in this section). Unlike traditional semiotic squares, the four terms $\mathrm{s}_{1}, \mathrm{~s}_{2}, \overline{\mathrm{s}}_{1}, \overline{\mathrm{s}}_{2}$ appear as positive terms society, nature, individuality, supernatural - but each (e.g., $s_{1}$ society) is also accompanied by its negation (e.g., $\overline{\mathrm{s}}_{2}$ not society) next to the term standing perpendicular to it (e.g., $\overline{\mathrm{s}}_{2}$ individuality). In doing so, we combine the traditional semiotic square with the semiotic square that the tool requires. Through implicature, each of the lexical items of the song has been placed with its appropriate abstract term - for example, "Do whatever you want" has been assigned to individuality because doing as you want implies individuality in the sense of freedom and uniqueness. Some lexical items share ascription to two or even three terms instead of one - thus, " 3 . IF go to church" suggests religion, wherefore it is supernaturally anchored, and society, in the sense of a traditional activity. Lexical items with shared ascriptions have been positioned in separate balloons hovering between terms. 
With regard to the kind of implicature used to assign lexical items to their corresponding terms, Pelkey follows a much more direct one than the one which can be attained with the tool. Thus for example, in Pelkey's $\mathrm{s}_{1}$ in Figure 5, "saving yourself for marriage" implies "virginity," which is a relatively direct and intuitive term to arrive at. The tool, on the other hand, interprets "saving yourself for marriage" as both 'not nature' and 'supernatural'. This double interpretation is arrived at by following Pelkey's implicature from "saving yourself for marriage" to virginity, but then a further implicature is added, from virginity to 'not nature' while there is a sex drive, there is no virgin drive - and 'supernatural' - virginity is a notion with strong religious and therefore supernatural overtones. This is the normal way in which the tool proceeds, through terms with intermediate abstracting power from which the more abstract terms of the CS-tool are arrived at. Whichever theory of categorization we use (Sinding 2010), thesauri work in the same way, although they can have up to three intermediate terms (Kay 2009), and standard procedures of validation in academic thinking bridge the gap between evidence and analytical claim by using concepts of varying intermediate abstracting power (Hayot 2014: 59-73; Headrick 2013). It should be noted that of the 43-44 lines the song consists of, only four could not be analyzed with the tool: "If you can't lose the weight/Then you're just fat/But if you lose too much/Then you're on crack." Losing (too much) weight, being fat and being on crack are not lexical elements which can be easily ascribed to any of the terms of the CS-tool.

In some cases, the exact attribution of the words of the song to the terms of the square is uncertain. Thus, for example, can "make lots of noise" really be abstracted as 'nature' and 'not society', as it appears in Figure 7? On its own, it surely cannot. However, attribution becomes possible if we take into account the co-text of the line - "So make lots of noise/Kiss lots of boys/Or kiss lots of girls" and its location within the argument - as a reaction to double binds - which suggests rebellious behavior and letting go of oneself to give expression to feelings or oneself. Even so, the doubt exists whether one should not better have added 'individuality' to the attribution. Slight adjustments such as these can thus be made to Figure 7. However, making them would not change the main distribution of colors, which can be seen in Figure 8.

The distribution of colors in Figure 8 is as follows: with regard to step 1, one of the ideological binds (red) mainly covers the area which leads from the center to the bottom left (society-supernatural-not natural), reaching individuality once. The other bind (blue) covers the area around nature, stretching once as far as society ("whore”), and also extending to 'not supernatural' and 'not society'. As regards step 2, the moment in which the narrative authorial voice shows awareness of its situation (green) is exclusively located in the field of society, which means that unlike the ideological binds, it does not touch on neighboring fields. Finally, 


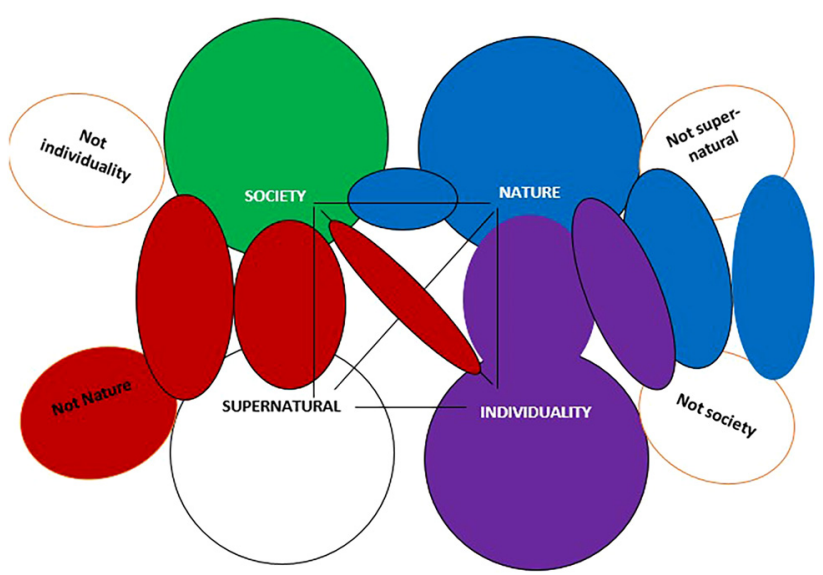

Figure 8: Cultural-semantic distribution of the lyrics in a semiotic square.

step 3, the moments in which the narrative/authorial voice breaks free from the double binds (violet) find their center in individuality but are vitally connected to nature and once to 'not society'.

Color distribution explains why society was used as the unmarked term in this semiotic square. Given the narrative progression of "Follow your Arrow," from establishing the double bind (step 1) to being aware of its meaning (step 2) and finally breaking free from it (step 3), the unmarked term should coincide with the overall meaning of the double bind which the narrative voice is aware of in step 2 . That awareness is an awareness of what is common to both ideological binds, the "them" typical of social imposition: "You're damned if you do [by them]/And you're damned if you don't [by them]/Can't win for losing/You just disappoint "em" (my italics). It is, however, precisely that unmarked status of society that makes the argument of the song suspect. At one point, the song refers to the trigger for breakthrough, which should again be common for both ideological binds. However, the language used to express that trigger is blatantly moralistic - "when the straight and narrow/gets a little too straight" - and thus corresponds to the views held by the 'red' ideological bind, the one vitally tied to society. The overall view of the double bind is thus expressed in terms of one of the binds, the moralizing, 'social' one.

Given that the terminology of one bind clusters so obviously around nature (blue) and the other connects with society (red), it is odd that the double bind as a whole is described in 'red', i.e., moralizing social terms. In fact, against the expectation that a social step 2 requires each of the binds in step 1 to connect with terms antagonizing society, the red bind systematically links the supernatural with 
society - going to Church, saving oneself for marriage and going to hell are all supernaturally grounded expressions which also encode moral condemnation or praise. In doing so, these expressions leave no 'pure' ascriptions to a view opposing society.

In step 3, oddity gives way to manipulation, for now a new concept is invoked which should escape nature and the combination society-supernatural of step 1 , as well as the socially inflected step 2 . This concept is individuality, epitomized by the title of the song and the lines "Follow your arrow/Wherever it points." However, in other expressions of individuality, the term is also associated with nature, the central concept of the 'blue' bind, for apart from the idea of choice and the underlying reference to homosexuality, there is no real difference between "not saving yourself from marriage," i.e., having sex (blue), and "kissing boys or girls" (violet). Both suggest different forms of physical contact, different expressions of natural affection or drive. Something similar can be said about other lines which belong to step 3, like "saying whatever you feel" or "loving who you love," which seemingly invoke freedom, choice and individuality, but at the same time express nature, doing what you want.

If the language of awareness (step 2) mimics the socialized language of the red bind and the language of breakthrough (step 3) is modeled on the naturalizing language of the blue bind, "Follow your Arrow" manipulates its listeners by selectively borrowing in step 2 and 3 from step 1 , and in systematic fashion. It does so by invoking choice to solve a dilemma, but expresses awareness of the dilemma in terms of, and thus criticizes, one of the options, and states the result of choice in terms of, and thus validates, the other option. Through the link between individual choice and the reduction of the individual in terms of the body - kissing, loving, expressing what you feel - the song is building up a classic emotionalist scenario, which has been variously theorized as the main ideology of modernity and postmodernity (MacIntyre 2007; Pinckaers 1995). Through this contradiction, the song is seen to build a straw man - society - to mask its own unmarked terms, individuality informed by nature.

Nor is this all. I remarked earlier that the CS-tool cannot make sense of four lines of the song, but after analysis with the CS-tool there is actually something relevant to say, not so much on the lines, but about their reference to intoxication and taking drugs, which reappears in three further moments in the lyrics (see Table 1).

The direction of drug-taking in the song is seemingly chaotic: it ranges from drinking to smoking cannabis - "joint" - or cocaine - "crack" - and drug taking can point to normal behavior - "As soon as you down the first one" - as much as to addiction - "you're on crack" - or abstinence - "you won't have a drink." It may be this chaotic appearance that induces Pelkey to diminish the significance of 
Table 1: Intoxication and taking drugs in "Follow your Arrow".

\begin{tabular}{|c|c|c|c|}
\hline Second double bind & Third double bind & $\begin{array}{l}\text { Breaking free (1st and } \\
\text { 2nd chorus) }\end{array}$ & $\begin{array}{l}\text { Breaking free (3rd } \\
\text { chorus) }\end{array}$ \\
\hline $\begin{array}{l}\text { If you won't have a drink } \\
\text { Then you're a prude } \\
\text { But they'll call you a } \\
\text { drunk } \\
\text { As soon as you down the } \\
\text { first one }\end{array}$ & $\begin{array}{l}\text { If you can't lose the } \\
\text { weight } \\
\text { Then you're just fat } \\
\text { But if you lose too } \\
\text { much } \\
\text { Then you're on } \\
\text { crack }\end{array}$ & $\begin{array}{l}\text { When the straight and } \\
\text { narrow } \\
\text { Gets a little too straight } \\
\text { Roll up the joint, or } \\
\text { don't } \\
\text { Just follow your arrow } \\
\text { Wherever it points, } \\
\text { yeah }\end{array}$ & $\begin{array}{l}\text { When the straight and } \\
\text { narrow } \\
\text { Gets a little too straight } \\
\text { Roll up the joint, I } \\
\text { would } \\
\text { Just follow your arrow } \\
\text { Wherever it points, } \\
\text { yeah }\end{array}$ \\
\hline
\end{tabular}

drug taking and proclaim its "core themes [as] more basic" (2017: 297). However, it is precisely because of the chaotic response of society to drug-taking that the chorus' emphasis on choice - "roll up the joint, or don't" - seemingly makes sense when the narrative / authorial voice apparently breaks through the double bind. In addition, the third chorus slightly modifies "roll up the joint, or don't" to "roll up the joint, I would" (my italics). This looks again like personal choice, and yet, given the contamination of individual choice by nature elsewhere, the lyrics can function as a vindication of drug taking not so much as a matter of choice, but as the natural thing to do because my body asks me to do so.

\section{Consequences for semiotic squares, interpretation, and embodiment}

In view of the results offered here, applying the CS-tool as a semiotic square offers results which differ from Pelkey's more standard use of the square. Generally speaking, Pelkey's results emerge in bottom-up fashion, are more local and work at the level of the sentence and through direct implicature. Implicature arises directly from the meaning of sentences, since the level of abstraction needed for implicature is relatively low. This means that analysis is very precise, but that not everything in the poem can be analyzed, since not every sentence can be fitted into a semiotic square. In contrast, analysis with the CS-tool operates top-down, approaches the whole poem, and validates abstractions through step-wise implicature and reference to the poem's language. During analysis, the results of implicature are sometimes less certain, since the terms which make up the semiotic 
square have been provided beforehand and are at a higher level of abstraction. On the other hand, while the assignment of terms may be less accurate, step-wise implicature allows for sufficient accuracy to establish overall distributions, wherefore an accurate picture of the argumentative structure of the poem is possible.

The overall picture arrived at with the CS-tool results in a completely different assessment of "Follow your Arrow." For Pelkey the song presents two repressive ideologies which the narrative/authorial voice is aware of and breaks free from, thus offering an alternative to the closed logic of the semiotic square. Analysis with the CS-tool shows something quite different: the two opposed ideologies are separated in misleading ways, as one of them is secretly in collusion with awareness, the other with the final breakthrough. By using the CS-tool the final breakthrough of the narrative/authorial voice appears as part of the system which the semiotic square describes. Analysis with the CS-tool is in the end more complete, for it is not restricted to those sentences to which semiotic squares can be applied stricto sensu. Because of the local and haphazard nature of Pelkey's analysis, and the fact that the semiotic square based on semes cannot inquire much beyond the logical structure of sentences, inconsistencies in those parts he does not really analyze (steps 2 and 3) go unnoticed. Pelkey's analysis lays bare the authorial/narrative voice of the poem and therefore functions as a surface analysis positing as a deep analysis of a superficial society. Analysis with the CS-tool uncovers the contradictions in that voice and therefore proposes that a deeper layer of analysis can be reached beneath the narrative/authorial voice. This in turn leads to the superficiality of Pelkey's depth. This is not to say that Pelkey's textual analysis is devoid of interest, for his analysis of the fourth double bind is ingenious (2017: 300) and provides a narrative progression with regard to the previous double binds. However, this analysis is still not complete, for the depth Pelkey uncovers hides a further depth, for which you need the CS-tool.

Beyond the differences between local-general analysis and direct-indirect implicature, the present comparative analysis with different semiotic squares has consequences for our understanding of the affordances of semiotic squares in general. The first concerns the possibility of stepping outside the semiotic square or remaining within the confines of the semiotic square during analysis. As we have seen (see end of Section 4), Pelkey believes with Jameson that semiotic squares both impose ideological closure, but that their very closure sharpens our wits to find a way out of that closure. In his analysis, "Follow your Arrow" provides textual and visual closure throughout step 1 and breakthrough throughout steps 2 and 3, a breakthrough which is, moreover encouraged by the very semiotic square Pelkey is applying (2017: 300). Analysis with the CS-tool maintains the opposite, that ultimately the semiotic square imposes itself and that what looks like freedom 
is really higher-order closure. There is of course the possibility that someone comes along and places a still higher-order doll on the already existing matryoshka, one which signals new escape from closure. There is also the obvious possibility that the cultural object we analyze cannot be analyzed with the CS-tool, or only up to a certain degree, and then comes up with something new which follows a completely different logic. I am in no way claiming exclusivity or exhaustiveness in all cases. In the case of "Follow your Arrow," however, I think analysis with the CS-tool ends discussion with regard to semiotic squares.

Of significance is also the completely different results arrived at with regard to $\overline{\mathrm{s}}_{2}$ by Pelkey and in the present analysis. Quoting Jameson, Pelkey proclaims $\overline{\mathrm{s}}_{2}$, "the negation of the negation," as both the term of "novelty" and "paradoxical emergence" (2017: 300) in the semiotic square in general and in the poem. If we analyze with the CS-tool and place society in unmarked position, as we have done, $\overline{\mathrm{s}}_{2}$ is the supernatural, a curiously empty concept, for every ascription to the supernatural is simultaneously an ascription to society (see Figures 7 and 8). We could revise the semiotic square by placing the real unmarked term of our analysis - unmarked because its manipulative power goes unnoticed in Pelkey's analysis - in $\mathrm{s}_{1}$ position. This term would be nature, as it contaminates individual choice. If we did so, $\overline{\mathrm{s}}_{2}$ would be individuality rather than the supernatural. For Pelkey this term comes last and lies outside the system, while in the CS-tool it may also come last, is therefore hidden and thus difficult to find, but is also the logical outcome of a predictable system. Again, analyzing "Follow your Arrow" with the CS-tool leaves no escape route open.

Of course, once we talk about $\bar{s}_{2}$ we have to ask ourselves what the results were of applying both $\overline{\mathrm{s}}_{1}$ and $\overline{\mathrm{s}}_{2}$ in both traditional form, as negations (not society, not nature), and in terms of the CS-tool, as positive terms (individuality, supernatural). As we can see in Figures 7 and 8, the analysis yields ascriptions in all the fields, whether they are traditional or not. I would argue that such a distribution places positive terms (nature, society, the supernatural and individuality) in a position of primacy with regard to negative values (not nature, not society, not the supernatural, not individuality). Let's follow the argumentative structure of "Follow your Arrow" where it first indicts the persona of the lyrics for being a "prude" which is a positive, specifically social because morally laden term - and then for being a "bore" - which is a negative term because it describes in terms of lack and cannot be sufficiently linked to positive terms. If we do so, the word "bore," which is more general than the word "prude" - you are rather a bore because you're a prude than the other way round - will nevertheless be drawn towards the signifying area of prude, precisely because "prude" defines positively and specifically and "bore" through absence and generally. In literary theory, there is the argument that characters defined via $s_{1}$ or $s_{2}$ threaten to reduce the richness of other 
characters defined via $\overline{\mathrm{s}}_{1}$ and/or $\overline{\mathrm{s}}_{2}$, as "the logic of opposition has it that negativity is vague by definition, if not void. It cannot be defined, hence, articulated, and as a result it remains unmanageable; indeed wild" (Bal 2009: 129). This is true enough if a character is defined by pure negativity. In "Follow your Arrow," however, and probably most texts, what we see is an argumentative structure which is defined both in terms of $\mathrm{s}$ and $\overline{\mathrm{s}}$. My impression is that in mixed cases, $\mathrm{s}$ gains ascendancy over $\bar{s}$. While the openness of pure $\bar{s}$ should thus always be respected, the mixed nature of so many texts suggests the appropriateness of operating with a semiotic square, such as the CS-tool, based on the existence of positive terms.

This leaves us with embodiment. Analysis following Pelkey and analysis with the CS-tool suggests that the presence of the body can be multi-valent in one and the same work with regard to thought-processes. Laterality and dextrality are found in both interpretations, only that in Pelkey's account they are located in manipulative society, which the authorial/narrative voice has to beware of, whereas the CS-tool locates them in the equally manipulative narrative/authorial voice. As for transversality, both Pelkey and the CS-tool find it in the embodied X of the jumping priest, only that again for Pelkey the embodied X leads to awareness of the strictures the semiotic square and from there to deliverance, whereas with the CS-tool the jumping priest points to the inescapability of semiotic squares and ideological manipulation.

\section{Conclusion}

The present article has tried to ground a cultural-semantic tool (CS-tool) in cognitive literary theory by presenting the tool as a semiotic square. The article has adapted the classic semiotic square to the requirements of the tool, basically by presenting a model based as much on $\mathrm{s}_{1}, \mathrm{~s}_{2}, \mathrm{~s}_{3}$ and $\mathrm{s}_{4}$ as on $\mathrm{s}_{1}, \mathrm{~s}_{2}, \overline{\mathrm{s}}_{1}$ and $\overline{\mathrm{s}}_{2}$. To ground this particular square in cognitive theory, the article benefited from Pelkey's validation of the semiotic square as embodied thinking. In addition, the article has drawn attention to the connection of modality with bioevolutionary theory to further validate the CS-tool in cognitive terms. The article has then compared Pelkey's analysis of the country song "Follow your Arrow" with the one that the CS-tool allows. The two analyses are complementary, but Pelkey's works more patchily on a more local level based on sentence units, and through direct implicature. The patchy, direct and local nature of the analysis follows the logic of the narrative/authorial voice and is therefore unable to ultimately uncover ideological inconsistencies in that voice. The CS-tool looks at the song from a position of higher abstraction which requires a three-step implicature, but can, because of that, move away from the sentence and look at the poem as a whole. 
This has consequences for the semiotic square, cognitive literary theory and literary theory in general. As regards the semiotic square, I would argue for a greater inclusivity of the semiotic square to include unusual forms. As regards cognitive literary theory and embodiment applied to the semiotic square, I would emphasize the multi-valency of embodiment, suggesting the possibility of closure and openness at one and the same time, depending on the level of analysis and the square used. Jameson's dictum that the closure of the semiotic square leads to awareness of closure and the possibility of escape from it can as easily lead to new closure as it can end in freedom. Only analysis of each specific text will show what the case is. Finally, if there is a lesson to be learned from a comparative analysis such as this it is that bottom-up analyses, such as Pelkey's, which uses the semiotic square but adapts its terms to the sentence analyzed, and top-down analyses, such as that effected with the CS-tool, which imposes its terms, need each other to create meaning. In the current environment of literary theory, in which I dare say bottomup reigns supreme and top-down is viewed with suspicion, occasionally some topdown comes in handy.

Research funding: None declared.

Author contribution: The author has accepted responsibility for the entire content of this submitted manuscript and approved submission.

Competing interest: The author declares no conflicts of interest regarding this article.

\section{References}

Adorno, Theodor W. \& Max Horkheimer. 1988. Dialektik der Aufklärung: Philosophische Fragmente. Frankfurt: Fischer.

Bal, Mieke. 2009. Narratology: Introduction to the theory of narrative. Toronto: University of Toronto Press.

Baumbach, Sybille, Ralph Haekel \& Ralf Sprang. 2017. Preface: Cognitive literary studies. Journal of Literary Theory 11. 161. https://doi.org/10.1515/jlt-2017-0017.

Candel, Daniel. 2013a. Advanced literacy and the place of literary semantics at secondary school. Semiotica 195(1/4). 305-330.

Candel, Daniel. 2013b. Literatur interpretieren: Ein analysetool. Stuttgart: Vandenhoeck \& Ruprecht.

Candel, Daniel. 2013c. Moving possible world theory from logic to value. Poetics Today 34(1-2). 177-231.

Candel, Daniel. 2016. Possible worlds in the history of the novel. Poetics Today 37(1). 107-136.

Candel, Daniel. 2018a. A report on the reports of the Stanford literary lab: A reason why the digital humanities may find it difficult to change literary history. Semiotica 224(1/4). 111-124. 
Candel, Daniel. 2018b. The rhythms of narrative tension and its cultural satisfaction: Frank Miller's 300. English Text Construction 11. 169-199.

Caracciolo, Marco. 2014. Interpretation for the bodies: Bridging the gap. Style 48(3). 385-403.

Caracciolo, Marco. 2016. Cognitive literary studies and the status of interpretation: An attempt at conceptual mapping. New Literary History 47(1). 187-207.

Carroll, Joseph. 2005. Human nature and literary meaning: A theoretical model illustrated with a critique of Pride and Prejudice. In Jonathan Gottschall \& David S. Wilson (eds.), The literary animal: Evolution and the nature of narrative, 76-106. Illinois: Northwestern University Press.

Colm Hogan, Patrick. 2015. The psychology of colonialism and postcolonialism: Cognitive approaches to identity and empathy. In Lisa Zunshine (ed.), The Oxford handbook of literary cognitive studies, 329-346. Oxford: Oxford University Press.

Cowart, Monica. 2014. Andy Clark, Antonio Damaso and embodied cognition. In Andrew Bailey (ed.), Philosophy of mind: The key thinkers, 259-281. London: Bloomsbury.

Crane, Mary Thomas. 2015. Cognitive historicism: Intuition in early modern thought. In Lisa Zunshine (ed.), The Oxford handbook of cognitive literary studies, 15-33. Oxford: Oxford University Press.

Doležel, Lubimír. 1998. Heterocosmica: Fiction and possible worlds. Baltimore: The Johns Hopkins University Press.

Easterlin, Nancy. 2012. A biocultural approach to literary theory and interpretation. Baltimore: Johns Hopkins.

Greimas, Algirdas \& François Rastier. 1968. The interaction of semiotic constraints. Yale French Studies 41. 86-105.

Hartner, Marcus. 2017. Bodies, spaces, and cultural models: On bridging the gap between culture and cognition. Journal of Literary Theory 11(2). 204-222.

Hayot, Eric. 2014. The elements of academic style: Writing for the humanities. New York: Columbia University Press.

Headrick, Paul. 2013. The Wiley guide to writing essays about literature. Chichester: WileyBlackwell.

Herman, David. 2013. Cognitive narratology. The living handbook of narratology. http://www.lhn. uni-hamburg.de/article/cognitive-narratology-revised-version-uploaded-22-september2013 (accessed 24 November 2018).

Hockett, Charles F. \& Stuart A. Altmann. 1968. A note on design features. In Thomas Sebeok (ed.), Animal communication: Techniques of study and results of research, 61-72. Bloomington: Indiana University Press.

Kay Christian. 2009. In Christian Kay (ed.), Historical thesaurus of the OED. Oxford: Oxford University Press.

Kukkonen, Karin \& Marco Caracciolo. 2014. Introduction: What is the second generation. Style 48(3). 261-274.

Lakoff, George \& Mark Johnson. 1980. The metaphors we live by. Chicago: Chicago University Press.

Liesbeth, Korthals Altes. 2014. Ethos and narrative interpretation: The negotiation of values in fiction. Lincoln: University of Nebraska Press.

MacIntyre, Alasdair. 2007. After virtue: A study in moral theory. Notre Dame: Notre Dame University Press.

Midgley, Mary. 2001. Wickedness: A philosophical essay. London: Routledge. 
Mortelmans, Tanja. 2007. Modality in cognitive linguistics. In Geert Brone \& Jeroen Vandaele (eds.), The Oxford handbook of cognitive linguistics, 869-889. Oxford: Oxford University Press.

Müller-Wood, Anja. 2017. Cognitive literary studies: On persistent problems and plausible solutions. Journal of Literary Studies 11(2). 223-239.

Nauze, Fabrice D. 2008. Modality in typological perspective. Amsterdam: Institute for Logic, Language and Computation.

Pelkey, Jamin. 2017. Greimas embodied: How kinesthetic opposition grounds the semiotic square. Semiotica 214(1/4). 277-305.

Peterson, Jordan B. 2018. Twelve rules for life: An antidote to chaos. Toronto: Random House.

Pinckaers, Servais. 1995. The sources of Christian ethics. Edinburgh: T\&T Clark.

Ricoeur, Paul. 1992. Oneself as another. Chicago: Chicago University Press.

Sinding, Michael. 2010. Framing monsters: Multiple and mixed genres, cognitive category theory, and gravity's rainbow. Poetics Today 31(3). 465-505.

Spaemann, Robert. 1994. Philosophische essays. Stuttgart: Reclam.

Sternberg, Meir. 2003. Universals of narrative and their cognitivist fortunes (I). Poetics Today 24(2). 297-395.

Sternberg, Meir. 2009. Epilogue: How (not) to advance towards the narrative mind. In Geert Brone \& Jeroen Vandaele (eds.), Cognitive poetics: Goals, gains and gaps, 455-532. Berlin: De Gruyter.

Varela, Francisco J., Eleanor Rosch \& Evan Thompson. 1991. The embodied mind: Cognitive science and human experience. Cambridge: MIT Press.

Vermeule, Blakey. 2015. The new unconscious: A literary guided tour. In Lisa Zunshine (ed.), The Oxford handbook of cognitive literary studies, 463-482. Oxford: Oxford University Press.

von Fintel, Kai. 2006. Modality and language. In Donald M. Borchert (ed.), Encyclopedia of philosophy, 20-27. Detroit: Macmillan Reference 2nd edn.

Wright, Georg H. 1968. An essay in deontic logic and the general theory of action. Amsterdam: North Holland.

Zunshine, Lisa. 2015. Introduction to cognitive literary studies. In Lisa Zunshine (ed.), The Oxford handbook of cognitive literary studies, 1-9. Oxford: Oxford University Press. 